\title{
DIREITO DE ACESSO À INFORMAÇÃO: UM INSTRUMENTO DE LIBERDADE POLÍTICA DOS CIDADÃOS
}

\section{RIGHT TO ACCESS TO INFORMATION: A CITIZENS ‘POLICY FREEDOM INSTRUMENT}

\author{
Hellen Nicacio de Araujo ${ }^{11}$ \\ Elda Coelho de Azevedo Bussinguer ${ }^{22}$
}

\begin{abstract}
Resumo: Este artigo analisa o direito fundamental ao acesso à informação pública como instrumento de liberdade do cidadão. Para tanto, questionamos: Como o direito fundamental à informação pode funcionar como instrumento para redução da interferência arbitrária na liberdade política dos cidadãos, na perspectiva da Teoria Neorrepublicana de Phillip Pettit? Neste sentido, através da revisão de literatura em uma perspectiva dialética, crítica, apresentamos o direito de acesso à informação pública, em especial o regramento trazido pela Lei de Acesso à Informação brasileira. Descrevemos os elementos conceituais da Teoria da Liberdade como Nãodominação de Phillip Pettit, especialmente sob o aspecto do exercício dos deveres da cidadania e da dominação do governo sobre a liberdade política dos cidadãos. Por fim, analisamos a aplicação do direito ao acesso as informações públicas às categorias da teoria de Pettit em especial, às estratégias para redução do "imperium". Concluímos que o direito à informação é um instrumento imprescindível para redução da interferência arbitrária na liberdade dos cidadãos, apesar de reconhecer que o maior desafio para o exercício da cidadania é a necessária mudança de atitude do cidadão brasileiro, que precisaria deixar a condição de expectador apático para se tornar o protagonista da vida política do país.
\end{abstract}

Palavras-chave: Acesso à informação. Cidadania. Teoria da Liberdade como não dominação.

\begin{abstract}
This article analyzes the fundamental right to access public information as an instrument of citizen freedom. Thus, we question: how can the fundamental right to Information act as an instrument for reducing arbitrary interference in the political freedom of citizens, from the perspective of the Neorepublican theory of Phillip Pettit? In this sense, through the literature review in a critical dialectical perspective, we present the right of access to public information, especially the rule brought by the Brazilian law of access to information. We describe the elements of the theory of freedom as a non-domination of Phillip Pettit, especially under the aspect of citizenship and government domination over the political freedom of citizens. Finally, we analyze the application of the right to access public information to the categories of Pettit theory in particular, to strategies to reduce the "imperium". We conclude that the right to information is an indispensable tool to reduce the arbitrary interference in the freedom of citizens, recognizing that the greatest challenge for the exercise of citizenship is the necessary change of attitude of the Brazilian, who would need to become the protagonist of the political life of the country.
\end{abstract}

Keywords: Access to information. Citizenship. Theory of freedom as non domination.

Recebido em 4 de agosto de 2019 Avaliado em 6 maio de 2020 (AVALIADOR A) Avaliado em 2 de maio de 2020 (AVALIADOR B)

Aceito em 11 de maio de 2020

\footnotetext{
1 Doutoranda em Direitos e Garantias Fundamentais na Faculdade de Direito de Vitória; Rua Marília de Rezende Scarton Coutinho, 194, Enseada do Suá, 29050-555, Vitória, Espírito Santo, Brasil; https://orcid.org/0000-0003-4303-4211; hbnicacio@gmail.com

2 Doutora em Bioética pela Universidade de Brasília; Coordenadora do Programa de Pós-graduação em Direito - Mestrado e Doutorado em Direitos e Garantias Fundamentais da Faculdade de Direito de Vitória; https://orcid.org/0000-0003-43034211; elda.cab@gmail.com
} 


\section{Introdução}

$\mathrm{Na}$ atual quadra da história brasileira, vivemos um momento de profunda instabilidade no cenário político nacional, permeado por escândalos de corrupção e desmandos com o dinheiro público.

Neste contexto, nos parece oportuno pensar nas formas da participação dos cidadãos nas decisões políticas do país, no sentido de tentar resgatar conceitos como: cidadania, democracia, república e interesse público, que, de há muito, estão ausentes dos espaços públicos nacionais.

Relacionamos ainda ao exercício da participação dos cidadãos na condução política do Estado, o direito fundamental de acesso às informações públicas, uma vez que para manifestar-se em um debate público de maneira consistente, o indivíduo ou o grupo social precisa ter acesso aos dados referentes à situação-problema, bem como as possíveis alternativas e consequências de cada escolha, tanto para si, quanto para sua comunidade.

Esse tema ganha especial relevância em uma quadra histórica na qual as chamadas Fake News ganham espaço nas mídias sociais e na vida das pessoas, causando confusão, desencontros, desinformação e levando a conclusões distorcidas sobre aspectos relevantes do cotidiano, influenciando na participação política do cidadão.

Para tanto, buscarmos o referencial teórico no Neorrepublicanismo de Phillip Pettit que, como se verá no decorrer deste artigo, fundamenta a sua Teoria na Liberdade como Não-dominação, em oposição ao conceito liberal de liberdade com não-interferência, buscando estabelecer formas de restringir ou extirpar as intervenções arbitrárias na liberdade política dos cidadãos.

Assim, tomando como base esse referencial teórico, buscamos compreender como o direito fundamental à informação pública pode funcionar como instrumento para redução da interferência arbitrária na liberdade dos cidadãos?

A partir de uma análise crítica dialética, apresentamos o direito fundamental de acesso à informação pública e sua importância para o exercício da cidadania, relacionando os diplomas normativos internacionais e nacionais que regem a temática, analisando, em especial, a Lei $\mathrm{n}$. 12.527/11 - Lei de Acesso à Informação (LAI) (BRASIL, 2011), que regulamentou o exercício desse direito no país.

No processo analítico da investigação utilizamo-nos da Teoria da Liberdade como Nãodominação de Phillip Pettit, buscando apresentar seus principais conceitos, elementos e estratégias, de forma a compreender os mecanismos de combate à dominação praticada pelo Estado em face de seus cidadãos.

A importância do direito fundamental de acesso à informação pública como instrumento para a redução da interferência arbitrária na liberdade política dos cidadãos em suas várias formas de utilização, foi analisada permitindo chegar uma resposta ou aproximação do problema. 


\section{0 direito fundamental ao acesso à informação pública e o exercício da cidadania}

O acesso à informação é um direito fundamental para o exercício da cidadania, uma vez que o cidadão, titular do poder soberano, precisa conhecer as decisões políticas tomadas pelos seus representantes, principalmente, onde e como são gastos os recursos públicos, para que possa exercer a sua função republicana de controle e fiscalização dos atos governo, bem como influenciar e participar das escolhas de interesse público.

Como aduz Leal (2011, p. 146) os níveis de democracia de uma sociedade são dependentes dos índices de informação e participação social em esferas de debate e decisão política que essa possui, sendo a única maneira legítima de propiciar ao cidadão se constituir como ator decisivo no processo democrático.

Trata-se, assim de um direito estratégico, que devido a sua importância, foi reconhecido como direito humano tanto pela ONU como pela OEA, em suas respectivas Declarações de Direitos Humanos, bem como no Pacto Internacional sobre Direitos Civis e Políticos (ORGANIZAÇÃO DAS NAÇÕES UNIDAS, 1948, 1966; ORGANIZAÇÃO DOS ESTADOS AMERICANOS, 1969).

Contudo, esses instrumentos internacionais apenas mencionam as garantias de liberdade de expressão e pensamento dos cidadãos, impondo barreiras à atuação do Estado, mas não fazem expressa referência ao direito de acesso à informação pública.

Apesar disto, a Comissão de Direitos Humanos da ONU, desde 1999, adota a interpretação de que o direito de acesso à informação dos órgãos públicos encontra-se protegido no Pacto Internacional sobre Direitos Civis e Políticos, isto porque no art. 19 desse diploma internacional foi assegurado o direito à liberdade de expressão, quem compreende a liberdade de procurar, receber e difundir informações e ideias de qualquer natureza, independentemente de considerações de fronteiras e de formas, sendo possível a sua restrição apenas para proteger a segurança nacional, a ordem, a saúde ou a moral públicas e o respeito aos direitos e reputação das demais pessoas.

Posteriormente, a OEA reconheceu expressamente, através da Resolução n. 1932 XXXIII-O/03, que o acesso à informação pública é um requisito indispensável para o funcionamento da democracia e que, em um sistema democrático representativo e participativo, os cidadãos exercem seus direitos constitucionais de participação política, por meio de ampla liberdade de expressão e livre acesso à informação, instando aos estados-membros a respeitar o direito à informação pública e de promover a edição de leis que assegurem o seu reconhecimento e efetivação (ORGANIZAÇÃO DOS ESTADOS AMERICANOS, 2003).

O Brasil, além de ser signatário dos Tratados Internacionais acima indicados, elencou o direito ao acesso à informação no rol dos direitos fundamentais, compreendendo o direito a receber dos órgãos públicos informações de seu interesse particular e de interesse coletivo ou geral, que 
serão prestadas no prazo da lei, sob pena de responsabilidade, ressalvadas aquelas cujo sigilo seja imprescindível à segurança da sociedade e do Estado (BRASIL, 1988).

Esse direito foi ainda reafirmado por meio do direito constitucional de petição que também confere aos cidadãos o direito de requerer informações aos Poderes Públicos para a defesa de direitos ou contra ilegalidade ou abuso de poder (BRASIL, 1988).

Tratando especificamente do dever dos Poderes Públicos de prestar informações aos cidadãos, a Constituição Federal consagrou o princípio da publicidade, como um dos cânones básicos da Administração Pública, o que implica na obrigação do Estado em divulgar as informações de interesse público para a sociedade, podendo ainda o cidadão ter acesso aos registros administrativos e a informações sobre atos de governo, na forma da lei (BRASIL, 1988).

Contudo, mesmo com a expressa menção no rol dos direitos fundamentais, os cidadãos ainda enfrentam muita resistência dos Poderes Públicos para ter acesso às informações públicas, principalmente com o argumento de que tal direito estava condicionado à existência de lei regulamentadora, ou seja, tratava-se de norma com eficácia limitada.

Assim, como observam Moroni (2009, p. 43) e Salgado (2015, p. 94) apesar da garantia constitucional conferida aos cidadãos, a velha cultura do sigilo e do domínio da informação como instrumento de poder, continuava a obstruir os canais de comunicação entre o cidadão e Administração Pública, sendo editados no período de 1937 a 2003, 64 instrumentos normativos, entre decretos, resoluções, portarias e etc., que procuraram dificultar o exercício a esse direito.

Desta forma, os cidadãos apenas eram informados sobre os atos da Administração Pública, por meio dos órgãos de comunicação governamental oficiais.

Todavia, a partir dos anos 1990, com a tentativa de implementar o modelo neoliberal no Brasil, houve uma mudança de paradigma em relação à divulgação de informações públicas, passando da comunicação governamental, cuja finalidade era ideológica e publicitária, especialmente no período do Estado Novo e na Ditadura Militar, para assumir uma nova feição direcionada para a transparência, eficiência e para a accountability (BRANDÃO, 2007, p. 6).

Neste contexto, foi editada a Lei Complementar n. 101/00 - Lei de Responsabilidade Fiscal - que estabeleceu como obrigação estatal a divulgação ampla dos instrumentos de gestão fiscal (BRASIL, 2000), sendo um marco da regulamentação da transparência ativa no país.

Mais recentemente, foi editada a Lei n. 12.527/11 - Lei de Acesso à Informação (LAI), que regulamentou o acesso à informação pública no Brasil. Esta lei estabelece que é dever do Estado garantir aos cidadãos o direito de acesso à informação, mediante procedimentos objetivos e ágeis, de forma transparente, clara e em linguagem de fácil compreensão. Determina, ainda, que os órgãos e entidades públicas devem promover, independentemente de requerimentos, ou seja, voluntariamente, a divulgação de informações de interesse coletivo ou geral, por eles produzidas ou custodiadas, em local de fácil acesso, inclusive, pela internet (BRASIL, 2011). 
Ou seja, a Lei de Acesso à Informação reforçou e disciplinou no Brasil a transparência ativa e passiva, fornecendo ao cidadão novas formas de controle do desempenho da Administração Pública.

Pela transparência ativa, o Estado tem o dever de disponibilizar, periódica e sistematicamente, informações sobre a gestão da pública para que que a população possa avaliar o desempenho governamental (YAZIGI, 1999, p. 8). É meio desta modalidade de transparência que Estado se obriga a publicar os indicadores de desempenho de suas atividades, os recursos e gastos públicos, bem como outros dados que permitem a avaliação e controle da gestão pública pelos cidadãos.

Por outro lado, na transparência passiva, o dever do Estado está em fornecer a todos os cidadãos, que o requeiram, o acesso a informações que estejam em seu poder, salvo aquelas que forem legalmente protegidas por motivo de segurança nacional, direito de terceiros ou procedimentos cuja divulgação antecipada possa provocar prejuízo ao cumprimento da função pública (YAZIGI, 1999, p. 9).

Assim, a regra geral no Brasil é o livre acesso às informações públicas, seja por meio da divulgação geral pelo Poder Público, seja através de requerimento realizado pelo cidadão.

Entretanto, este direito não é absoluto, havendo previsão constitucional expressa de sigilo das informações quando for imprescindível à segurança da sociedade e do Estado, ou seja, diante de questões de segurança, o sigilo prevalece sobre o direito de informação, podendo ser negado o acesso a informações públicas (MARTINS, 2014, p. 137), salvo quando elas forem necessárias à tutela judicial ou administrativa de direitos fundamentais ou diante de condutas que impliquem violação dos direitos humanos praticada por agentes públicos ou a mando de autoridades públicas (BRASIL, 2011).

Assim, diante dessas situações excepcionais, a lógica se inverte e o direito ao acesso às informações públicas volta a prevalecer, ainda que este gere risco à sociedade e ao Estado.

A LAI determina ainda que os poderes públicos disponibilizem para população suas informações de caráter geral, por meio das Tecnologias de Informação e Comunicação (TICs), principalmente a internet, o que objetiva possibilitar maior transparência e comunicação entre cidadãos e o governo, facilitando a difusão de informações, bem como na formação das opiniões políticas e de interação direta da esfera civil com a esfera política.

Contudo, para que esse objetivo seja alcançado necessário se faz, também, ampliar o acesso das pessoas à rede mundial de computadores, visto que ainda há uma grande parcela da sociedade que não está integrada às tecnologias, ou à sociedade em rede, como expõe Castells (2006, p. 18), caso contrário, o acesso às informações públicas, mais uma vez, ficará restrito apenas àqueles que dispõem de recursos financeiros para o acesso as TICs, o que viola o ideal democrático. 
Outro dado relevante constante na Lei de Acesso à Informação é a dispensa de justificativa para o requerimento realizado pelo cidadão, ou seja, o pedido de informação pode ser feito sem a necessidade de motivação.

Para Martins (2014, p. 143) a desnecessidade de motivação do pedido permite que o direito de acesso à informação possa se transformar em instrumento de rivalidade política ou de tumulto para a rotina administrativa.

Entretanto, essas questões não podem ser consideradas mais importantes do que o acesso dos cidadãos às informações dos órgãos públicos, seja porque a transparência é um dever do gestor, seja porque se trata de um direito baseado no regime republicano e democrático adotado pelo Estado Brasileiro.

Exigir que o cidadão apresente seus motivos para ter acesso a qualquer informação do poder público, além de criar óbice desnecessário, ainda permite que o gestor faça juízo de valor sobre o interesse do requerente, facilitando omissões deliberadas e a seleção de informações disponibilizadas, o que vai de encontro ao objetivo final do direito à informação como mecanismo de preservação e defesa do interesse público.

Neste sentido, a desnecessidade de justificar o pedido para ter acesso a informações dos órgãos públicos, apresenta-se como um relevante instrumento de transparência e do exercício da cidadania.

Assim, com todo esse aparato normativo, o cidadão brasileiro teria instrumentos jurídicos para, por meio do direito à informação, exercer o controle e a fiscalização dos atos dos Poderes Públicos, no exercício da democracia e no cumprimento de sua função republicana de zelar pela virtude cívica.

No entanto, na realidade, mesmo após a edição da LAI, que reforça os princípios constitucionais e estabelece prazos e procedimentos facilitados para o exercício do direito de acesso a informações públicas, o Estado mantém viva a velha cultura do controle e da utilização da informação como forma dominação, ou seja, sem qualquer compromisso com o interesse comum (PETTIT, 2010, p. 14).

Logo após a publicação da LAI, o governo federal editou o Decreto n. 7.724/12, no qual, a pretexto de regulamentar a LAI, limitou o acesso à informação, pois estabeleceu que não seriam admitidos requerimentos de informações que forem considerados: genéricos; desproporcionais ou desarrazoados; que exigissem trabalhos adicionais de análise, interpretação ou consolidação de dados e informações, serviços de produção ou tratamento de dados que não sejam de competência do órgão ou entidade (BRASIL, 2012).

Desta forma, ao estabelecer por meio de Decreto, supostamente regulamentar, critérios mais rigorosos que os previstos na Lei, além de tornar letra morta o dispositivo contido no $\$ 3^{\circ}$ do art. 10 da Lei de Acesso à Informação, o ato da então Presidente da República, claramente, 
dificultou o acesso à informação pública, violando a democracia e os princípios de liberdade política dos cidadãos.

Recentemente, foi editado mais um Decreto Federal - Decreto n. 9.690/2019, no qual foi ampliado o rol das autoridades que poderiam classificar documentos públicos como ultrassecretos (BRASIL, 2019).

A classificação de documentos como ultrassecretos impede o acesso público as informações pelo prazo de 25 (vinte e cinco anos), sendo esse o mais alto grau de sigilo do Estado brasileiro. Por esse motivo, apenas poucas autoridades públicas, cujo rol foi estabelecido da LAI, tem o poder de aplicar essa tamanha restrição a documentos públicos. Contudo, o Decreto n. 9.690/2019 autorizou a delegação do poder de classificar documentos como ultrassecretos para outras autoridades, tais como: dirigentes de autarquias, de fundações, de empresas públicas e de sociedades de economia mista, conferindo um poder excepcional e de utilização restrita para indivíduos que ocupam cargos de confiança e de indicação política, em evidente afronta aos princípios que norteiam da Lei de Acesso a Informação (BRASIL, 2019).

Recentemente esse Decreto Presidencial teve a sua eficácia suspensa pela Câmara dos Deputados, sendo, posteriormente, revogado pelo próprio Presidente da República. ${ }^{3}$

Mas, além destes golpes normativos sofridos pela LAI, não podemos deixar de considerar a força da cultura do sigilo, que se apresenta sem cerimônia na Administração Pública brasileira, seja pela criação de obstáculos não previstos na lei, como a exigência da presença física do requerente no protocolo do órgão, seja na simples omissão ao questionamento realizado.

Em interessante pesquisa realizada pela ONG Transparência Brasil foram enviados pedidos de informação a 206 órgãos públicos de todos os poderes e esferas federativas. Essa entidade questionou os órgãos públicos a respeito dos pedidos de informação, baseados na LAI, recebidos por eles. Contudo, apenas 30 (trinta), ou seja, 15\% (quinze por cento) concederam integralmente o acesso à informação solicitada pela ONG (TRASNPARÊNCIA BRASIL, 2017, p. 1).

\footnotetext{
Em mais uma tentativa de dificultar o acesso à informação, em março de 2020, foi editada a Medida Provisória n. 928/20, que estabeleceu algumas medidas para o enfrentamento a emergência de saúde pública decretada em razão do novo coronavírus, dentre elas, a suspensão dos prazos de resposta a pedidos de acesso à informação nos órgãos cujos agentes públicos estejam em regime especial de trabalho e que dependam de acesso presencial dos encarregados da resposta ao setor envolvido; a necessidade de reiteração dos pedidos pendentes de resposta após o encerramento do estado de calamidade pública e, por fim, a vedação de interposição de recursos contra negativas de resposta (BRASIL, 2020). A referida MP foi objeto de 3 (três) Ações Diretas de Inconstitucionalidade (ADI ns. 6351, 6347 e 6353) perante ao STF, tendo sua eficácia suspensa mediante a concessão de liminar, pelo Min. Alexandre de Moraes, referendada pelos demais membros da Corte. Em sua decisão, o relator ressaltou que a publicidade e a transparência ganharam especial relevância neste momento em que os gestores públicos estão autorizados a realizar a aquisição de insumos e serviços para fazer frente à pandemia, mediante dispensa de licitação. Lembrou ainda que a Constituição Federal consagrou o princípio da publicidade como um dos vetores fundamentais à administração pública, conferindo-lhe absoluta prioridade na gestão administrativa e garantindo pleno acesso às informações a toda a sociedade. Neste sentido, a referida Medida Provisória objetivou transformar a exceção, que é o sigilo, em regra, afastando a incidência dos princípios da publicidade e da transparência (SUPREMO TRIBUNAL FEDERAL, 2020). Esse voto foi seguido pelos demais Ministros que salientaram a necessidade de garantir ao cidadão o pleno acesso às informações solicitadas, sob pena de responsabilização política, civil e criminal, salvo nas hipóteses constitucionais de sigilo. Esta nota explicativa foi acrescida em 08/05/20, dado que a decisão do STF foi publicada em 30 de abril de 2020.
} 
Esses dados não deixam dúvidas que há muito para ser mudado na Administração Pública brasileira para que alcancemos patamares mínimos de transparência e de compromisso com os pilares da República, o que demonstra a necessidade de ampliar a discussão sobre os limites da atuação do Estado em face dos direitos e deveres dos cidadãos.

Assim, para o aprofundamento teórico da análise desta relação entre o Estado e os seus cidadãos, buscamos o referencial na Teoria da Liberdade como Não-dominação de Phillip Pettit, que nos auxilia a compreender a dominação promovida pelo Estado contra a liberdade política do cidadão, bem como os mecanismos que podem ser opostos a ela.

\section{0 ideal de liberdade política como não dominação de Phillip Pettit}

O ideal de liberdade possui um papel fundamental para a filosofia política, sendo matriz para diferentes correntes de pensamento, uma vez que a partir do seu conceito, constroem suas ideias sobre democracia, direito e cidadania, sendo este também o ponto central da Teoria neorrepublicana da Liberdade Política como Não-dominação de Phillip Pettit.

O Neorrepublicanismo é movimento filosófico de origem acadêmica anglófona que busca resgatar valores antigos do republicanismo clássico, especialmente o renascentista romano, em oposição ao liberalismo americano.

Em seus diversos ramos, os filósofos neorrepublicanistas utilizam, com intensidade diferentes, valores como:

a) virtude cívica, designando a defesa das liberdades, o envolvimento na comunidade, o amor às leis e à pátria, a contínua preferência do interesse público e a busca do bem comum, em oposição à corrupção;

b) a participação política, que envolve um alargamento do processo de discussão e deliberação onde todos possam participar em condições de igualdade no acesso à arena pública;

c) a razão dialógica, como modo adequado de alcançar o bem comum, que se traduz num compromisso conversacional, como forma de compreender e resolver as discórdias;

d) soberania popular, que se traduziria na liberdade relacionada ao princípio eletivo;

e) a modelização da cidadania, como reconstrução do papel do homem na sociedade política, através da conversa cívica e da participação na polis, onde são acentuados os deveres e as responsabilidades, como ideal de liberdade, ou seja, um cidadão numa república age e participa na comunidade, de forma que se veja como autor e destinatário da lei para fundamentar argumentos políticos e filosóficos atuais (PINTO, 2001, p. 468-470). 
Phillip Pettit, filósofo político irlandês, buscou no republicanismo romano, especialmente em Maquiavel, o fundamento para construir a sua teoria sobre a liberdade, que se opõe ao pensamento liberal norte-americano dos anos 60.

Para esse autor, apesar das diferentes concepções de liberdade, pode-se constatar que tradicionalmente distingue-se o ideal político de liberdade em duas formas, uma negativa e outra positiva, como se não houvesse mais qualquer outra possibilidade.

A concepção do ideal de liberdade política constituída por dois polos, positivo e negativo, foi cunhada por Isaiah Berlin que afirma existirem dois sistemas de ideias que dão respostas diferentes e conflitantes para uma questão central da política: a relação entre obediência e da coerção (BERLIN, 2002, p. 228).

Para Berlin (2002, p. 229) a liberdade política positiva teria origem na polis grega aristotélica, sendo por isso chamada de neoateniense. Segundo esta concepção, a liberdade do indivíduo se manifesta pela sua participação na vida política, sendo, em sua essência, a busca pelo autogoverno da pólis. É importante observar que neste contexto, a liberdade é o próprio agir político (ação positiva), mesmo que isso implique na perda de liberdades individuais, que poderão ser suprimidas em favor de um bem comum, abrindo a possibilidade para governos tirânicos e totalitários (BERLIN, 2002, p. $142,163,218)$.

Por outro lado, a liberdade política negativa se refere ausência de interferência, ou seja, no agir sem ser importunado ou limitado por outros. Assim, quanto mais opções e alternativas tem o indivíduo maior será a sua liberdade, posto que não há liberdade "se outros me impedem de fazer o que do contrário eu poderia fazer" (BERLIN, 2002, p. 229). Esta concepção está baseada na ausência de algo, no caso da interferência, por isto denominada negativa.

Analisando o sistema dicotômico de Berlin, Pettit aponta duas caraterísticas que identificam a concepção da Liberdade como Não-interferência. A primeira se refere à lei, que, mesmo visando assegurar à liberdade, acaba por restringi-la, mesmo que a interferência envolvida seja apenas a "imposição constitucional de um estado de direito justo, mas (necessariamente) coercitivo." (PETTIT, 2010, p. 39).

Neste sentido, Pettit aduz que a Teoria liberal incorre em erro ao não perceber que existem diferentes formas de interferência.

Como observa Pettit (2007, p. 186-187) há Estados que são governados por autoridades que não são eleitas pelo povo, que podem legislar casuisticamente, em vez de acolher a lei geral; onde não precisam defender suas decisões, não existindo forças opositoras. Por outro lado, há Estados que são geridos por autoridades que são cidadãos comuns perante a lei, que se submetem a eleições e a críticas populares, que devem governar sobre os princípios da lei. No primeiro caso, o Estado tem um poder arbitrário de interferência sobre o cidadão, no segundo, a interferência não pode ser considerada arbitrária porque exercida dentro dos limites da lei. 
Assim, existiria uma grande diferença entre o poder relativamente não arbitrário, que o Estado exerce quanto aplica uma punição a um criminoso, e o poder totalmente arbitrário, quando o indivíduo ou corporação obstrui ou coage alguém em benefício próprio, manipulando suas escolhas ou criando atmosfera na qual o indivíduo se sente intimidado.

O que Pettit defende é que as leis condicionem a todo e qualquer cidadão, que embora seja um caso óbvio de interferência, desde que se faça em consonância com os interesses comuns, elas não representam um tipo arbitrário de intromissão/limitação, não podendo ser consideradas uma afronta à liberdade, uma dominação (SILVA, 2011, p.39).

A segunda característica da Liberdade como Não-interferência seria que ela está vinculada, obrigatoriamente, a uma interferência real ou de fato, desprezando situações de dominação em que, mesmo no campo potencial, interferem no agir do indivíduo, limitando as suas escolhas.

Assim, o filho de um pai emocionalmente instável ou o aluno cujo professor decide, de forma arbitrária, de quem gosta e de quem não gosta, entre outros, são exemplo apontados por Pettit (2007, p. 189-190) para ilustrar a situação de domínio, que mesmo que não seja exercida de fato, a simples possibilidade do mal, condiciona, censura, inibe o agir do indivíduo. Nestes casos, a dominação sobre a vida do outro é tão intensa quanto o efeito causado pela interferência de fato, não havendo sentido em estabelecer que apenas a interferência real seria capaz de macular a liberdade do cidadão.

Diante destas críticas, o referido autor propõe uma terceira via para o estudo da liberdade política, diversa da liberdade positiva e negativa, uma possibilidade republicana: a Liberdade como Não dominação, que advém da antiga tradição republicana que associa ser livre a não ser dominado ou subjugado por ninguém.

Essa tradição remonta a antiga constituição romana, mais precisamente no Digesto, de onde se depreende que ser livre é não ser escravo, ou seja, não estar sob o domínio de outra pessoa, podendo agir conforme sua própria vontade.

Para Pettit (2007, p. 192), o ideal de Liberdade Política como Não dominação é mais completo, tanto do ponto de vista sociológico quanto do constitucional, que o ideal de não-interferência, posto que ao mesmo tempo em que é capaz de enxergar ausência de liberdade onde o liberalismo vê seu gozo (dominação em potência), o ideal de não-dominação também é capaz de ver liberdade onde os liberais veem seu comprometimento (interferência não-arbitrária).

Segundo Silva (2007, p. 205) ao se definir pela ausência de algo, a Teoria de Pettit compartilha a preocupação liberal de evitar consequências potencialmente ameaçadoras às liberdades individuais associadas à ideia de liberdade positiva. Contudo, nela o que deve estar ausente não é qualquer tipo de interferência intencional de terceiros, mas exclusivamente aquelas formas que podem ser qualificadas como arbitrárias ou de dominação. 
A interferência arbitrária acontece quando o agente tem a possibilidade de agir de acordo com sua vontade, sem levar em consideração os interesses daqueles que serão atingidos por suas ações.

Assim, para que haja dominação é necessário:

a) que o agente tenha a capacidade para interferir nas ações alheias;

b) que ele aja de acordo com a sua vontade (arbitrium) e com impunidade, ou seja, sem que haja a previsão de punição para o ato;

c) que haja a possibilidade de interferir sobre certas escolhas que os outros indivíduos estão em posição de fazer;

d) IV) dupla consciência sobre esse domínio, tanto por parte dos poderosos, quanto por parte dos dominados.

A dominação pode se manifestar por meio de comportamentos que impliquem na coerção sobre corpo, como restrição de movimentos; coerção sobre vontade, mediante ameaça de punição, ou por meio da manipulação, como formação capciosa e irracional de crenças ou desejos (PETTIT, 2010, p. 15).

Segundo Pettit (2010, p. 23) as relações de dominação podem ocorrer em várias circunstâncias, principalmente diante da ausência de uma cultura de direitos humanos; da falta de oportunidades de emprego e controle das relações de trabalho ou de instrumentos de equilíbrio das relações civis, bem como na ausência de instrumentos de defesa dos cidadãos contra os agentes públicos que gozam poder sobre a população.

Neste sentido, a dominação pode ser compreendida em duas modalidades: o dominium e o imperium. A primeira modalidade ocorre pela relação de interferência arbitrária entre os concidadãos (indivíduos ou grupos), como nas relações entre empregados e empregadores privados. A segunda envolve a relação entre o Estado e os cidadãos. Ambas as modalidades são perniciosas, mas a dominação exercida pelo poder público em face de seus cidadãos é mais difícil de ser enfrentada porque há poucos instrumentos de contestação. Ademais, de nada adiantaria estabelecer instituições ou tomar iniciativas que reduzam a dominação relacionada ao dominium se esses mesmos instrumentos ampliarem a dominação associada ao imperium (PETTIT, 1999, p. 175).

A partir deste paradigma, a filosofia Neorrepublicana de Pettit se propõe a refletir sobre quais seriam os limites que poderiam ser impostos ao Estado para que ele seja uma força direcionada ao bem comum e não uma fonte de danos à comunidade.

A resposta para esta questão foi encontrada por Pettit em institutos republicanos: o constitucionalismo e a democracia.

Para Pettit, um regime constitucional que defenda a liberdade e não seja manipulado pelos governantes deve cumprir três condições. 
A primeira condição é que o regime constitucional seja baseado no império da lei. Para tanto, lei deve ser promulgada e levada ao conhecimento público antes de sua aplicação, sendo inteligível, consistente e não sujeita a mudanças constantes. Deve ainda ter aplicabilidade universal, sendo todos os cidadãos, inclusive, os detentores de poder, sujeitos a ela indistintamente.

Ainda no tocante a condição referente ao império das leis, quando o governo se deparar com uma situação em que não haja lei clara, deve submeter as suas decisões ao processo legal, não agindo discricionariamente.

Pettit compreende que por mais que o aparato jurídico em uma República seja bem ordenado, sempre haverá uma margem de discricionariedade à disposição dos governantes, devendo essa ser restringida ao máximo, posto que quanto maior a discricionariedade menor será a proteção da sociedade contra a dominação.

A segunda condição apontada por Pettit é a divisão das funções do Estado, já que a concentração de poder em uma única instituição favorece a interferência arbitrária. Entretanto, do ponto de vista republicano, não basta à clássica separação e independência dos poderes Legislativo, Executivo e Judiciário, sendo igualmente relevantes o Federalismo: que concede maior grau de autonomia dos governos regionais em relação ao central, e Bicameralismo no âmbito do legislativo, de forma que sendo este composto por duas casas com composição diversa, possa ampliar os debates dos mais diversos interesses.

A terceira condição do regime constitucional republicano é a necessidade de aumentar o rigor para mudanças das leis, principalmente aquelas operadas pela vontade das maiorias circunstanciais representadas no poder. Pettit (1999, p. 186) alerta para os perigos do que ele qualifica como populismo, defendendo a proteção das minorias contra a força maioritária, rompendo, assim, com a tradição política e constitucional que busca a legitimidade das leis na vontade da maioria do povo.

Para o autor, essa proteção contramajoritária requer uma jurisprudência baseada na "boa lei", que segundo o republicanismo, deve ser identificada pelo critério do ideal de Liberdade como Não dominação e não pela referência de ter apoio da maioria da população; sugerindo ainda que essa jurisprudência seja guiada pelas normas dos "bons costumes e virtudes cívicas" reconhecidas historicamente, por sua capacidade de responder as expectativas da comunidade.

Como observado por Rodrigues (2010, p. 52) no neorrepublicanismo de Pettit para o bom funcionamento da República além das leis, é necessário que existam regras de conduta social, como os bons costumes e as virtudes cívicas, em verdadeira relação de complementariedade, de forma que uma dê sustentação a outra e vice-versa, jamais podendo estar em conflito, mas sempre em perfeito equilíbrio.

Neste sentido, somente quando apoiadas em normas adequadas, originadas e reforçadas por uma civilidade amplamente difundida, é que as leis republicadas e os cidadãos disfrutarão de liberdade como não dominação (PETTIT, 1999, p. 320). 
Entretanto, por mais completo que seja o constitucionalismo, ele não é suficiente para conter totalmente o "imperium", principalmente porque sempre existirá certo grau de discricionariedade nas mãos das autoridades públicas, sendo fundamental a participação da população para que a discricionariedade não se transforme em dominação, comprometendo a liberdade política dos cidadãos.

Como afirmado por Elias (2008, p. 50) do ponto de vista republicano, há uma estreita conexão entre democratização e aumento da Liberdade como Não-dominação, uma vez que essa, necessariamente, obriga que na tomada de decisões pelo poder público seja levado em conta os interesses e ideais dos que serão afetados, diminuindo a possibilidade de arbitrariedade.

Assim, em relação à democracia Pettit (2007, p. 220-221) sugere a adoção de um modelo bidimensional, que compreende a dimensão eleitoral e a contestatória.

Segundo o autor, o Estado deveria ser democraticamente forçado a trilhar todos os interesses comuns assumidos pela comunidade, ou seja, deveriam existir instituições democráticas que possibilitassem conhecer e autorizar as decisões políticas, examinando outros fatores que influenciam na maneira como elas se materializam de forma a extirpar os fatores que não atendem ao interesse público. Então, as instituições democráticas devem ter uma dimensão positiva, com a finalidade de buscar e identificar, e uma dimensão negativa, que visa examinar e vetar.

Com relação à dimensão positiva, o autor aponta que, por meio do processo eleitoral periódico aqueles que estão no governo são submetidos ao controle popular, podendo ser destituídos de seus mandatos ou rejeitados em futuras eleições. Ademais, por meio da democracia eleitoral legitimam-se as decisões tomadas pelo governo, uma vez que a seleção daqueles que estão no poder é determinada pela população.

Na República democrática, os cidadãos através do processo eleitoral, assumem um papel "autoral", pois são eles que escolhem os mandatários que serão autores das leis e das decisões políticas que serão executadas pelo governo. Desta forma, eles são autores indiretos de qualquer política que os representantes apresentem durante o mandato.

Por outro lado, aqueles que exercem ou pretendem exercer um cargo público eletivo estão sob constante pressão dos eleitores para assumirem e defenderem os interesses da comunidade, devendo, por isto, sempre estar atentos às demandas comuns dos cidadãos, o que aumentará suas chances de eleição ou reeleição, já que demonstra compromisso com a vontade geral, ou, pelo menos com sua base eleitoral.

Todavia, Pettit (2007, p. 224) alerta que a dimensão eleitoral da democracia não satisfaz todas as exigências do republicanismo, já que ela não oferece proteção contra a adoção de políticas que apenas representam o interesse da maioria, discriminando e até perseguindo a minoria. Ele observa que essas estratégias são muito comuns, sobretudo, próximo do pleito eleitoral, em que os candidatos pretendem a renovação dos seus mandatos e, para tanto, buscam o apoio da maioria. 
Esta situação tem sido muito presente nas democracias liberais atuais, principalmente, com o avanço dos partidos e líderes conservadores, que pregam abertamente medidas contra grupos minoritários, que, por sua vez, têm reagido de forma bastante enérgica, causando focos de conflitos em vários países, como, por exemplo, a França, Alemanha, Estados Unidos da América e no Brasil.

Outro risco apontado por Pettit (2007, p. 224) é o da democracia eleitoral se tornar apenas um jogo de interesses, onde alguns mandatários podem propor medidas extremamente corporativistas, sem qualquer relação com o interesse comum, já que povo é autor apenas indireto dos projetos.

Neste aspecto, Pettit chama atenção para o problema do lobby exercido pelos grupos detentores de poder, que se utilizam de agentes públicos para promover decisões que, apenas na aparência e nos discursos, são de interesse comum, mas que no fundo apenas representam os interesses das elites, o que, lamentavelmente, é bem comum nos dias atuais.

Por fim, o autor alerta que a democracia eleitoral representa apenas o anseio do autogoverno do povo, o que não implica, necessariamente, na liberdade política das pessoas, posto que além do povo como expressão coletiva, a eliminação da dominação depende de que "não apenas que o povo considerado coletivamente não possa ser ignorado pelo governo, mas também que o povo considerado separadamente ou atomizadamente não possa sê-lo." (PETTIT, 1999, p. 178).

Diante destas críticas, o filosofo irlandês sugere a adoção de uma dimensão negativa da democracia, denominada de democracia contestatória onde pessoas ou grupos possam contestar a decisão tomada pelo governo, caso considere-a contrária aos seus interesses e ideias relevantes.

É importante destacar que não se trata de um modelo no qual qualquer cidadão tenha o poder de vetar toda e qualquer decisão política que afete interesses das minorias ou de pessoas particulares. Primeiro, porque este tipo de manifestação seria impraticável no mundo atual; segundo, porque há decisões que são orientadas pelo interesse público, destinadas a reduzir ou eliminar as interferências arbitrárias, que podem beneficiar mais alguns indivíduos que outros. Nessas hipóteses, o poder de veto ao invés de assegurar, comprometeria ainda mais a Liberdade como Não-dominação.

Entretanto, é possível que o Estado adote medidas que os cidadãos ou grupos afetados julguem que estão em desacordo com os interesses da comunidade a que pertencem, sendo, assim, necessário que eles tenham acesso a fóruns públicos para contestar tais decisões.

O que Pettit sugere não é a necessidade do consentimento explícito de cada cidadão em relação a cada uma das políticas adotadas pelo Estado, mas sim, a possibilidade de contestação, ou seja, de dizer não, para garantir a não-dominação.

Neste sentido, bastaria um consentimento implícito, ou seja, a falta de protesto ou impugnação para gerar a evidência da aceitação da medida adotada pelo governo. Assim, a legitimidade da decisão política estaria na ausência de impugnação e não no consentimento. 
Como afirmado por Elias (2008, p. 54) dentro do ideal republicano, para que as decisões públicas sejam democráticas elas devem ser passíveis de contestação, podendo a impugnação ser originada de qualquer seguimento da sociedade. Neste modelo, o governo será democrático na medida em que assegure que as tomadas de decisão, no administrativo, no legislativo, nos tribunais, levem em conta as inquietudes e modos de pensar dos cidadãos, pois se isto não acontecer, as decisões serão passíveis de contestação.

Pettit enumera três precondições que precisam ser satisfeitas para que o Estado seja democrático no sentido contestatório.

A primeira precondição é que a democracia seja deliberativa, ou seja, as decisões públicas sejam tomadas com base no diálogo racional, transparente, com ampla liberdade de acesso a informações e discussões, podendo, inclusive, os representantes do governo serem instados a prestar informações e justificar suas decisões, de modo a oferecerem uma base para que os cidadãos possam legitima-las ou contesta-las.

Contudo, para que a tomada de decisão pública seja considerada não arbitrária sob o prisma Neorrepublicano de Pettit, os cidadãos precisam ter certeza de que seus interesses são levados em consideração, para tanto, é necessário que a base de tomada de decisão seja o debate, e não a barganha.

Para Pettit (2010, p. 373) nas decisões baseadas na barganha, as pessoas comparecem com seus interesses e ideias pré-definidos e os acertos são realizados por meio de concessões mútuas, onde todos buscam assegurar um acordo de benefício comum. Já nas decisões tomadas com base no debate, os indivíduos partem do reconhecimento comum da relevância de certos interesses, buscando alcançar um acordo que melhor corresponda ao que todos consideram relevante. Nesta modalidade, qualquer um pode ser capaz de justificar-se de maneira plausível contra a decisão tomada e não apenas àqueles que tenham poder de barganha.

Todavia, apesar de tratar da democracia deliberativa, o foco de Pettit não está na formação de consensos, mas que ela seja um instrumento pelo qual cada um possa expor seus argumentos e que eles sejam levados igualmente em consideração, em um processo racional de diálogo.

A segunda precondição para uma democracia ser contestatória é que ela seja inclusiva, ou seja, que ela acomode os mais diversos grupos sociais, mormente os grupos que representam as minorias circunstanciais, de forma a oferecer canais para que todos os seguimentos, não apenas as elites, exprimam suas contestações e opiniões.

Neste sentido, são justificáveis medidas que promovam a inclusão dos setores minoritários no debate público, inclusive com ações afirmativas para corrigir a sub-representação de determinados grupos no Parlamento, no Executivo e no Judiciário.

Silva (2007, p. 215) aduz que a democracia inclusiva pode beneficiar-se bastante da presença de movimentos sociais ativos, uma vez que eles podem desempenhar a função de clarear e 
canalizar em direção aos fóruns estatais, às contestações emergentes entre cidadãos, principalmente componentes de grupos sociais menos favorecidos.

A terceira precondição é que a democracia seja responsiva, uma vez que, além de uma base e de um canal para contestação, os cidadãos devem ter garantia que suas manifestações sejam efetivamente consideradas pelos poderes públicos.

Pettit (1999, p. 193) elenca uma série de possíveis canais para que as contestações possam ser ouvidas, dentre elas: a escrita de uma carta para um membro do parlamento; o direito de apelar a uma corte superior contra uma decisão judicial, além de prerrogativas menos formais tais como: o direito de associação, protesto e manifestação popular.

Assim, a democracia contestatória cria um ambiente de teste para decisões políticas, que devem se submeter a possíveis contestações. Esse ambiente enfatiza o ideal republicano de "leis virtuosas", que foram testadas pelo tempo e a ideia de que o povo tem o direito de resistir e contestar as medidas com características arbitrárias. A contestação confere à democracia uma "dimensão editorial." (PETTIT, 1999, p. 180).

Esta modalidade democrática é de natureza negativa, uma vez que os cidadãos participam para dizer não, para conter ou corrigir, em nome dos interesses comuns assumidos pela comunidade, algo já criado pelo povo coletivo, autor indireto das decisões políticas (SILVA, 2007).

É importante ressaltar que na democracia contestatória o cidadão republicano pode impugnar apenas as decisões que são contrárias aos interesses comuns da sociedade, participando do processo político, dizendo não às leis e decisões que interferem arbitrariamente em suas liberdades, e não da defesa de interesses exclusivamente pessoais.

Entretanto, além do constitucionalismo e da democracia contestatória, Pettit (2010, p. 29), propõe algumas estratégias para a redução ou a eliminação da subjugação, que ampliariam a Liberdade como Não-dominação.

A primeira estratégia proposta por Pettit (2010, p. 29-30) é proteção dos impotentes. Essa proteção seria viabilizada pela criação de instituições protetoras, reguladoras e empoderadoras dos indivíduos e grupos mais vulneráveis e minoritários da comunidade.

O referido autor não indica quais seriam essas instituições nem, tampouco, estabelece que tipo de relações poderiam se dar entre elas, mas confere especial atenção para as instituições protetoras.

Afirma o autor que a proteção do indivíduo em nossa sociedade é realizada por meio de instituições que têm um sistema de defesa não-ameaçador, assim como o Estado de Direito de caráter não voluntarista, podendo ser legal, consuetudinário ou constitucional, desde que disponha de um sistema de normas protegido contra a atuação da maioria, inclusive parlamentar, visando assegurar os direitos da minoria. Ele deve ter algumas características, como a generalidade, a transparência, a não-retroatividade e a coerência, de forma que a lei não seja um recurso de dominação de qualquer indivíduo ou grupo. 
A segunda estratégia revela a preocupação de Pettit com o controle dos recursos dos poderosos, inclusive do governo. Esses recursos são instrumentos comuns para subjugar os indivíduos ou grupos de pessoas, a menos que seus poderes sejam devidamente regulados, através de medidas como: eleições regulares, discussão democrática, limitação de exercício de cargos, separação dos poderes, possibilidade de apelação e revisão, provisão de informação, entre outras.

Contudo, Pettit (2010, p. 31) chama atenção para o fato de que a política não é o único âmbito onde é possível a utilização de recursos para dominar os indivíduos, lembrando o poder econômico, nas relações privadas, e o poder cultural também são instrumentos de dominação que precisam ser controlados por meio de medidas como: regulações contra a demissão sem justa causa; proibição do trabalho infantil; combate contra fraudes contábeis; ações contra manipulação de informações, instituição de códigos de conduta e de tribunais de protestos, criação de fóruns para contestação, etc.

A terceira estratégia seria empoderar certas pessoas e grupos, promovendo igualdade em capacidades básicas, como educação, transporte, saúde, assistência jurídica, visando protegê-las contra diversas formas de subjugação e de vulnerabilidade.

Esse empoderamento é principalmente assegurado via iniciativas do Estado de bemestar social, especialmente através da educação para todos e universal acesso a serviços culturais importantes, como transporte e comunicação; além de outras medidas como: seguridade social, seguro acidente e assistência jurídica, de forma que os indivíduos se tornem mais resistentes às diversas formas de interferência por parte de outrem, e, assim, menos vulneráveis à dominação (PETTIT, 2010, p. 32).

Todavia, as estratégias contra a dominação não estão de modo algum restritas as iniciativas estatais, podendo operar-se, inclusive com grande impacto, também pela sociedade, através das organizações civis como: os movimentos sociais, movimentos de consumidores, movimentos ambientais, movimentos feministas, sindicatos dos trabalhadores, associações de liberdade civil e até mesmo as forças competitivas do mercado.

As medidas para a promoção da Liberdade como Não-dominação que vimos discutindo são concebidas com o fim de reduzir a intensidade e a abrangência da interferência arbitrária de algumas pessoas sobre outras e, em especial, do Estado contra o cidadão. Contudo, a concepção de liberdade republicana não se limita ao esquema de autoproteção, mas estende-se para um regime de proteção legal universal, de forma que requer não somente a proteção dos indivíduos para que não sejam dominados, mas sim a expansão da possibilidade de fazer escolhas.

Neste sentido, a liberdade como não-dominação compreende um aspecto subjetivo e intersubjetivo, uma vez que, para que as suas condições surtam efeito dependem do conhecimento comum entre as partes envolvidas na relação. Isso significa que o gozo da liberdade republicana está associado à capacidade de "olhar nos olhos do outro", confiante que se está no conhecimento 
compartilhado de que não é em função da permissão desse outro que o indivíduo faz suas escolhas, mas devido a ser uma pessoa na plenitude de seus direitos legais e sociais (PETTIT, 2010, p. 35-37).

Esta relação de consciência da não-dominação e de confiança também deve permear a relação entre os cidadãos e o governo, que devem ser livres, não por uma concessão do Estado, mas por ser a razão de sua própria existência, uma vez que na República as instituições e as leis são necessárias para o bem-estar dos cidadãos e não para que sejam dominados por elas.

\section{0 direito fundamental à informação como instrumento para redução da interferência arbitrária na liberdade política dos cidadãos}

O direito fundamental de acesso à informação pública inegavelmente possui a finalidade de proporcionar ao cidadão o conhecimento dos fatores que interferem na tomada das decisões políticas, principalmente em relação a sua compatibilidade com as questões de interesse público, viabilizando a sua participação efetiva na condução do governo.

Entretanto, apesar de o Brasil ter adotado a forma republicana desde 1889, os cidadãos brasileiros tiveram pouquíssima possibilidade de interferência nas decisões políticas, que sempre foram tomadas pelas elites do país, muitas vezes influenciadas por forças econômicas estrangeiras.

Neste contexto, a participação popular, quando muito, era apenas formal, expressada apenas por meio das eleições, mas sem que os cidadãos pudessem conhecer efetivamente o que acontecia no interior do governo.

Por outro lado, devido completa desconexão entre a população e os atos governamentais, havia muito pouca identificação com o real sentido da democracia republicana, dotada de valores morais nos quais o cidadão deve ser o garantidor da sua própria liberdade política, por meio da constante vigilância sobre atos dos governos, sendo esta tarefa impossível sem que haja acesso à informação pública.

É ainda interessante observar que, desde o governo do presidente Nilo Peçanha, há no Brasil um órgão estatal responsável para fazer a comunicação governamental, mas as informações divulgadas eram selecionadas e supervisionadas pelos Ministros de governo, impedindo que a população tivesse acesso efetivo às informações dos poderes públicos, o que só se agravou com a propaganda ideológica do Estado Novo e a censura no período da Ditadura Militar (DUARTE, 2002, p. 2).

Assim, a cultura do sigilo, do domínio da informação como instrumento de poder, impedia o cidadão de exercer o seu direito republicano de controlar os atos do governo, em clara infração ao interesse público, ou seja, no exercício de uma interferência arbitrária praticada pelo Estado, ou seja, imperium, segundo o conceito de Phillip Pettit.

Com a redemocratização do país, os movimentos em favor de maior participação popular conseguiram incluir no texto da Constituição de 1988, o direito fundamental de acesso às informações públicas, bem como estabelecer o dever dos Poderes Públicos darem publicidade aos seus atos. 
Entretanto, apesar da mudança operada na Constituição, como afirmado acima, os cidadãos permaneciam sem instrumentos legais para combater a negativa ao acesso à informação pública, uma vez que não havia regulamentação para o exercício do direito, o que só ocorreu 23 anos após a promulgação da Carta Magna, através da Lei de Acesso à Informação.

Segundo Salgado (2015, p. 94) essa Lei tem como objetivo promover, de maneira efetiva, a participação do cidadão na gestão pública, o desenvolvimento democrático, incentivando o ideal republicano e o controle social do poder, além de reforçar a publicidade nas práticas estatais.

A participação efetiva dos cidadãos nas decisões políticas do país é, nos termos da Teoria de Pettit (2007, p. 220-221) um elemento fundamental para a implementação do ideal de Liberdade como Não-dominação, especialmente no que se refere ao modelo bidimensional de democracia, no qual os cidadãos participam positiva e negativamente da condução política do país.

$\mathrm{Na}$ dimensão eleitoral, na qual a participação dos cidadãos se dá pela escolha de seus representantes, o direito de acesso à informação pública é instrumento fundamental para a realização de sua função: conhecimento-autorização, uma vez que será através dele que os cidadãos terão ciência dos atos praticados pelos seus representantes, podendo escolher aqueles que efetivamente possuem compromisso com o interesse público, reforçando os seus próprios laços com a democracia.

Conforme observado por Martins (2011, p. 234) sem a oportunidade de conhecer a fundo seus representantes, de tomar nota de suas decisões e de seus atos administrativos, a população estabelece laços frágeis com o sistema democrático, posto que a crença nas instituições públicas e em seus integrantes depende de sua transparência.

Assim, para que o cidadão possa escolher seus candidatos para ocuparem os cargos públicos é indispensável, como aduz Carvalho (1999, p. 35) que o cidadão esteja "interado" de todas as circunstâncias e consequências de sua opção e isso só ocorrerá se dispuser de informações sérias, seguras e imparciais sobre os atos dos agentes públicos candidatos a cargos eletivos ou a reeleição.

Neste sentido, por meio do acesso à informação, o cidadão tem a possibilidade de conhecer o conteúdo dos atos políticos praticados pelos agentes públicos, seja por meio de documentos oficiais (agendas, contratos, decisões administrativas, projetos de lei, vetos do executivo, atuação parlamentar) disponíveis nos sites dos órgãos e poderes públicos, ou pela transmissão direta pelos canais públicos de televisão, que disponibilizam os pronunciamentos dos parlamentares nas Casas Legislativas, de forma que a população conheça a atuação do candidato na vida pública, podendo fazer as suas escolhas.

O cidadão pode ainda requerer, gratuita e diretamente, aos órgãos públicos as informações de seu interesse, que não estejam disponíveis no site ou através do Serviço de Informações ao Cidadão (SIC), que deverão ser respondidas no prazo de 20 dias, prorrogável por mais 10 dias, salvo se protegidas por sigilo, desde que não enquadradas como hipóteses do seu afastamento (BRASIL, 2011).

Assim, através do direito de acesso às informações públicas, o cidadão poderá tanto identificar o mandatário que possui compromisso com interesse público quanto o que não possui 
engajamento para realização dos interesses gerais, de forma que estes últimos não sejam mais reconduzidos aos cargos políticos.

Outra importante vertente desse tema é a obrigatoriedade de publicidade dos planos de governo dos candidatos à eleição para a chefia do Executivo.

Segundo a Lei n. 9.504/97 (BRASIL, 1997) os candidatos aos cargos do Executivo devem apresentar à Justiça Eleitoral, juntamente com o seu requerimento de registro de candidatura, a sua plataforma ou plano de governo com o intuito de dar publicidade das suas intenções, propiciando discussões e comparativos entre as diversas plataformas.

O acesso a esses documentos permitiria, em tese, que os cidadãos levassem em consideração as propostas de cada candidato, principalmente no que se refere aos temas da saúde, educação, segurança, transporte, entre outros na hora de escolher a quem conceder seu voto, sendo importante instrumento de informação para o cidadão, que deveria estar disponível no site do Tribunal Eleitoral, mas que pode ser obtido mediante requerimento do cidadão.

Porém, convém asseverar que não se considera que o acesso a essas informações seja a panaceia que curará todos os males do processo eleitoral, principalmente porque, na maioria das vezes, os atos contrários ao interesse público são simulados, revestidos de uma aparente compatibilidade com os objetivos comuns da comunidade, mas podem apresentar-se como indícios, principalmente para cidadãos atentos e cônscios de seus deveres para com a República, para orientar na escolha de seus representantes.

Na dimensão contestatória da democracia, direito de acesso à informação é ainda mais relevante porque está na base da atuação cidadã.

O direito de acesso à informação pública permite que os cidadãos conheçam o conteúdo dos atos políticos, dos orçamentos públicos, das políticas públicas e das leis, mesmo quando ainda estão em fase de elaboração, como, por exemplo, o projeto de lei, podendo contestar àquelas que contrariem os interesses da comunidade, visando afastar o imperium (PETTIT, 1999, p. 175).

Neste sentido e considerando as precondições estabelecidas por Pettit temos que, no que se refere à democracia contestatória deliberativa, como observado por Salgado (2015, p. 91) a configuração do Estado brasileiro estabelecida na Constituição Federal de 1988 (BRASIL, 1988), traz uma série de princípios e de instrumentos para a participação direta dos cidadãos, em espaços públicos de discussão, sobre decisões políticas, tais como os Conselhos ou órgãos colegiados de formação e fiscalização das políticas públicas, como os Conselhos municipais e estaduais de Saúde, bem como a previsão de audiências públicas nas Comissões do Congresso Nacional, onde são discutidos os projetos de lei.

Entretanto, para ocuparem esses espaços públicos em condições de manterem um diálogo racional torna-se imprescindível que os cidadãos tenham acesso às informações públicas e estejam imbuídos do espírito republicano, de forma que possam influenciar as decisões e, principalmente de opor-se a elas, com argumentos contundentes e baseados na razão e no interesse público. 
Já no que se refere à democracia contestatória inclusiva, que objetiva oferecer canais para que todos os seguimentos, não apenas as elites e maiorias exprimam suas contestações, o direito ao acesso a informações públicas não é menos relevante, principalmente quanto exercido pelos movimentos sociais, que lutam pelos direitos das minorias e pela defesa dos direitos humanos, de forma que, de posse das informações públicas, especialmente em relação às políticas públicas, possam dizer não, àquelas que se opõem aos interesses dos grupos mais vulneráveis.

A terceira precondição para a democracia contestatória é que ela seja responsiva, ou seja, que cidadãos tenham a garantia de que suas manifestações sejam efetivamente consideradas pelos poderes públicos. Ela pressupõe a existência de uma comunicação entre os cidadãos e o Estado, posto que de nada adianta a possibilidade de contestação se ela não reverbera nas decisões dos poderes públicos.

Como observa Moroni (2009, p. 40), o controle social do Estado não quer dizer apenas a consulta ao Estado ou a questão do acesso à participação, mas diz respeito ao cidadão participar efetivamente do destino da nação, o que só será possível se as suas contestações forem ouvidas.

Neste aspecto, se revela a importância de canais de comunicação, principalmente através da Tecnologia de Informação e Comunicação prevista na LAI, em especial as redes sociais, que atualmente têm sido muito utilizadas para estabelecer canais diretos de comunicação entre os cidadãos e seus representantes, especialmente parlamentares, inclusive como instrumento de pressão e contestação diante de medidas políticas que colocam em risco o interesse público.

Ademais, também, através do acesso às informações públicas, o cidadão poderá acompanhar os atos praticados pelos seus representantes, após a sua contestação, de forma a saber se as suas impugnações foram ouvidas ou não, o que permitirá a adoção de outras medidas, tanto na seara eleitoral, com não recondução do agente público, quanto na seara judicial, caso haja a violação de uma norma jurídica.

Entretanto, além da democracia em suas duas dimensões, Pettit (2010, p. 29-30), propõe estratégias para a redução da dominação estatal e exercício da cidadania, sendo a primeira delas a proteção dos impotentes por meio de instituições de proteção, regulação e empoderamento.

No âmbito estatal, a Lei de Acesso à Informação estabeleceu dois órgãos recursais para revisão das decisões administrativas que neguem o acesso à informação pública: a Controladoria da Geral da União e a Comissão Mista de Reavaliação de Informações (BRASIL, 2011).

Essas duas instituições tem a função de proteção do direito do cidadão de ter acesso a informações de interesse público para que possa exercer o seu múnus republicano de controle e fiscalização dos atos do poder público, o que é de fundamental importância, principalmente diante cultura de sigilo dos órgãos estatais, mormente quanto às informações podem gerar consequências indesejáveis para os poderosos.

Por outro lado, a própria sociedade civil também tem se organizado para criação de instituições privadas, geralmente organizações sociais sem fins lucrativos, para a promoção do 
controle das atividades desenvolvidas pelos poderes públicos, cuja função pode variar tanto no auxílio ao acesso à informação e sua decodificação para que se torne de fácil compreensão para o cidadão, quanto na abertura de espaços de debates públicos relacionados à atuação dos governos e dos governantes.

Essas ONGs podem ser classificadas tanto como instituições de proteção quanto de empoderamento para o cidadão, uma vez que não apenas divulgam e explicitam dados públicos muitas vezes de difícil acesso e compreensão, bem como expõem os vícios das políticas públicas, mas, principalmente, fomentam a participação dos cidadãos para o exercício de seus deveres republicanos.

A segunda estratégia revela a preocupação de Pettit com os recursos do governo, o que diz respeito ao controle e a discussão democrática sobre os orçamentos públicos.

Como apontado por Barcellos (2005, p. 99) o controle das políticas públicas depende de informações sobre os recursos públicos disponíveis, bem como sobre a previsão e a execução orçamentária.

Contudo, a mesma autora afirma que o acesso a essas informações é bastante precário, sendo apontadas as seguintes dificuldades: I) No campo das receitas públicas, diversos orçamentos não distinguem a arrecadação prevista para cada tributo, o que dificulta saber, por exemplo, de quanto serão os investimentos mínimos em saúde e educação, uma vez que devem ser calculados com base em um combinado de receitas oriundas de tributos específicos; II) No que se refere às despesas, a dificuldade é ainda maior, tanto no que diz respeito às previsões orçamentárias quanto no que toca à execução do orçamento, isto é, às despesas de fato realizadas, já que em diversos orçamentos constam apenas uma verba geral para despesas, sem especificação; III) Os relatórios de execução orçamentária nem sempre existem e, em geral, são pouco informativos, contendo rubricas bastante amplas, como, por exemplo, "encargos especiais", ou despesas de órgãos públicos sem que se possa saber ao certo o que foi investido na atividade fim do órgão, como saúde e educação, e o que foi gasto com outras despesas, como publicidade, remuneração de servidores e etc. (BARCELLOS, 2005, p. 99).

Assim, ao dificultar o acesso às informações sobre os itens que compõem os orçamentos públicos, o Estado inviabiliza o controle político sobre os recursos públicos, sendo um campo onde a transparência ativa precisa ser aprimorada, posto que não basta disponibilizar os dados em tempo real, como determina a Lei de Responsabilidade Fiscal, esses dados precisam ser claros e inteligíveis, como previsto na Lei de Acesso à Informação, para que população possa fiscaliza-los adequadamente.

Ressalte-se que como estabelecido na própria LAI o acesso à informação não se restringe a visualização de códigos de difícil compreensão, que em nada colaboram para a República, mas deve ser garantido por meio de informações claras e em linguagem de fácil compreensão, de forma a garantir que o cidadão, efetivamente, compreenda o conteúdo das informações fornecidas e, através delas, possa formar o seu juízo de valor cívico, seja para legitimar os atos do governo seja para contesta-los. 
A terceira estratégia seria o empoderamento certas pessoas e grupos visando protegê-las contra diversas formas de subjugação e de vulnerabilidade. Neste contexto é de fundamental importância à atuação do próprio Estado, através de seus diversos órgãos e instituições, como a Defensoria Pública e o Ministério Público, que devem desempenhar suas funções na defesa dos cidadãos e da sociedade, especialmente no que se refere às prerrogativas da cidadania e a defesa do interesse público, contra a dominação estatal, sendo o acesso às informações públicas imprescindível para a eficácia destas ações.

Contudo, esse papel não é exclusivo do Estado devendo a própria sociedade se engajar neste mister, notadamente por meio dos movimentos sociais e das instituições de defesa da cidadania, que por meio de suas ações podem fomentar o engajamento das pessoas para a defesa de suas liberdades políticas, incentivando os cidadãos a exercer o controle das decisões políticas do Estado, sendo o direito de acesso às informações públicas um fundamental instrumento para que possam reduzir interferências arbitrárias praticadas pelos poderes públicos.

Por fim, como afirmado por Pettit, o ideal de liberdade como não dominação, para além de pretender extinguir as interferências arbitrárias, visa estabelecer uma relação de confiança entre o governo e os cidadãos, onde ambos saibam que as decisões políticas são baseadas nas virtudes cívicas, levando-se em consideração os interesses e o bem-estar de todos os cidadãos.

\section{Conclusão}

Neste artigo foi tratado do direito fundamental ao acesso a informações públicas pelos cidadãos, sendo reconhecida sua natureza de direito humano fundamental para o exercício da democracia, tanto na seara internacional quanto nacional.

Apesar de constar no rol de direitos fundamentais desde a promulgação da Constituição Federal/88, o direito de acesso às informações públicas só foi regulamentado em 2011, pela Lei 12.527, que além de reafirmar a necessidade da transparência ativa e passiva, regulamentando um procedimento simples para os pedidos de informação, inovou ao determinar que os poderes públicos disponibilizassem suas informações de interesse geral através da internet, o que visa facilitar ainda mais o acesso para os cidadãos, que deve se dar de forma clara e em linguagem de fácil compreensão.

Contudo, lamentavelmente, a cultura do sigilo e do domínio da informação como forma de poder, ainda se mostra presente e potente na Administração Pública brasileira, seja resistência dos poderes públicos em responder os pedidos formulados pelos cidadãos e instituições da sociedade civil, seja pela edição de normas infralegais que objetivam restringir e/ou dificultar o acesso às informações ou que ampliem a possibilidade de classificação de sigilo de documentos públicos.

Por outro lado, através do referencial da Teoria de Liberdade como Não dominação de Phillip Pettit foi possível observar que o direito de acesso a informações públicas é de fundamental importância para o exercício dos deveres cidadania, tanto no aspecto da democracia eleitoral quanto 
na contestatória, mas também como instrumento imprescindível de proteção, empoderamento e controle de recursos visando à redução da interferência arbitrária na liberdade política dos cidadãos.

Contudo, apesar de sua relevância política para a cidadania e para democracia, e da existência de instrumentos normativos, o maior desafio para o exercício da cidadania é a necessidade de despertar nos cidadãos o interesse e o compromisso com a condução do Estado, uma vez que isto implica em uma mudança radical de perspectiva do cidadão que passaria da condição de expectador apático, que sempre foi alijado das decisões políticas, para a posição protagonista da vida política do país, para além de manifestações em redes sociais, o que depende de um processo de conscientização e empoderamento, que apesar de algumas tentativas, especialmente promovidas pelas ONGs e movimentos sociais, ainda nos parece muito incipiente e facilmente cooptável por manobras midiáticas e fake news.

\section{Referências}

BARCELLOS, Ana Paula de. Neoconstitucionalismo, Direitos fundamentais e controle das políticas públicas. Revista de Direito Administrativo, Rio de Janeiro, v. 240, p. 83-105, abr. 2005. Disponível em http://bibliotecadigital.fgv.br/ojs/index.php/rda/article/view/43620/44697 Acesso: em 28 jan. 2020.

BERLIN, Isaiah. Dois conceitos de Liberdade. Estudos Sobre a Humanidade: Uma antologia de ensaios. São Paulo: Companhia das Letras, 2002.

BRANDÃO, Elizabeth Pazito. Conceito de comunicação pública. Comunicação Pública: Estado, mercado, sociedade e interesse público, São Paulo, v. 2, p. 1-33, 2007. Disponível em: http://fasam. edu.br/wp-content/uploads/2016/07/Historia-da-Comunica\%C3\%A7\%C3\%A3o-P\%C3\%BAblica. pdf. Acesso em: 10 fev. 2020.

BRASIL. Constituição. República Federativa do Brasil de 1988. Brasília, DF: Senado Federal, 1988. Disponível em: http://www.planalto.gov.br/ccivil_03/constituicao/constituicao.htm. Acesso em: 1 fev. 2020.

BRASIL. Decreto n. 7.724, de 16 de maio de 2012. Regulamenta a Lei n. 12.527, de 18 de novembro de 2011, que dispõe sobre o acesso a informações previsto no inciso XXXIII do caput do art. $5^{\circ}$, no inciso II do $\mathbb{3} 3^{\circ}$ do art. 37 e no $\$ 2^{\circ}$ do art. 216 da Constituição. Diário Oficial da União, Brasília, DF, 16 maio 2012. Disponível em: http://www.planalto.gov.br/ccivil_03/_ato2011-2014/2012/decreto/d7724.htm. Acesso em: 2 fev. 2020.

BRASIL. Decreto n. 9.690, de 23 de janeiro de 2019. Altera o Decreto n ${ }^{\circ} 7.724$, de 16 de maio de 2012, que regulamenta a Lei n ${ }^{\circ}$ 12.527, de 18 de novembro de 2011 - Lei de Acesso à Informação. Diário Oficial da União, Brasília, DF, 24 jan. 2019. Disponível em: http://www.planalto.gov.br/ ccivil_03/_ato2019-2022/2019/decreto/D9690.htm. Acesso em: 29 jul. 2020.

BRASIL. Lei Complementar n. 101, de 4 de maio de 2000. Estabelece normas de finanças públicas voltadas para a responsabilidade na gestão fiscal e dá outras providências. Diário Oficial da União, Brasília, DF, 5 maio 2000. 
BRASIL. Lei n. 9.504, de 30 de setembro de 1997. Estabelece normas para as eleições. Diário Oficial da União, Brasília, DF, 1 out. 1997.

BRASIL. Lei n. 12.527, de 18 de novembro de 2011. Regula o acesso a informações previsto no inciso XXXIII do art. $5^{\circ}$, no inciso II do $\mathbb{S} 3^{\circ}$ do art. 37 e no $\mathbb{2} 2^{\circ}$ do art. 216 da Constituição Federal; altera a Lei $\mathrm{n}^{\circ}$ 8.112, de 11 de dezembro de 1990; revoga a Lei $\mathrm{n}^{\circ} 11.111$, de 5 de maio de 2005, e dispositivos da Lei no 8.159, de 8 de janeiro de 1991; e dá outras providências. Diário Oficial da União, Brasília, DF, 18 nov. 2011. Disponível em: http://www.planalto.gov.br/ccivil_03/_ato20112014/2011/lei/112527.htm. Acesso em: 1 fev. 2020.

BRASIL. Medida Provisória n. 928, de 23 de março de 2020. Altera a Lei n. 13.979, de 6 de fevereiro de 2020, que dispõe sobre as medidas para enfrentamento da emergência de saúde pública de importância internacional decorrente do coronavírus responsável pelo surto de 2019, e revoga o art. 18 da Medida Provisória n. 927, de 22 de março de 2020. Diário Oficial da União, Brasília, DF, 23 mar. 2020. Disponível em: http://www.planalto.gov.br/ccivil_03/_ato2019-2022/2020/Mpv/ mpv928.htm. Acesso em: 30 abr. 2020.

CARVALHO, Luis Gustavo Grandinetti Castanho. Direito de informação e liberdade de expressão. Rio de Janeiro: Renovar, 1999.

CASTELLS, Manuel. A sociedade em rede: do conhecimento à política. In: CASTELLS, Manuel; CARDOSO, Gustavo. A sociedade em rede: do conhecimento à acção política. Lisboa, Portugal: Imprensa Nacional Casa da Moeda, 2006. Disponível em: http://www.egov.ufsc.br/portal/sites/ default/files/anexos/a_sociedade_em_rede_-_do_conhecimento_a_acao_politica.pdf. Acesso em: 2 abr. 2020.

DUARTE, Jorge. Assessoria de imprensa no Brasil. Assessoria de imprensa e relacionamento com a mídia: teoria e técnica. São Paulo: Atlas, 2002. v. 4. Disponível em http://www.cfn.org.br/eficiente/ repositorio/intranet/ideias/779.pdf. Acesso em: 10 fev. 2020.

ELIAS, Maria Lígia Ganacim Gramado. Democracia e participação política no novo republicanismo: um estudo sobre o pensamento de Phillip Pettit. 2008. Dissertação (Mestrado em Sociologia Política) - Universidade Federal de Santa Catarina, Florianópolis, 2008. Disponível em https://repositorio. ufsc.br/xmlui/handle/123456789/92002. Acesso em: 2 jan. 2020.

LEAL, Rogério Gesta. A difícil relação entre o direito fundamental à informação e o acesso aos documentos produzidos pelo regime militar brasileiro. Revista de Direito Brasileira, Florianópolis, v. 1, n. 1, p. 141-172, jul. 2011. Disponível em: http://www.rdb.org.br/ojs/index.php/rdb/article/ view/56. Acesso em: 28 jan. 2020.

MARTINS, Paula Lígia. Acesso à Informação: Um direito fundamental e instrumental. Acervo, Rio de Janeiro, v. 24, n. 1, p. 233-244, jan./jun. 2011. Disponível em: http://www.revistaacervo.an.gov. br/index.php/revistaacervo/article/view/381/381. Acesso em: 28 jan. 2020.

MARTINS, Ricardo Marcondes. Direito fundamental de acesso à informação. A\&C - Revista de Direito Administrativo \& Constitucional, Belo Horizonte, ano 14, n. 56, p. 127-146, abr./jun. 2014. Disponível em: http://www.revistaaec.com/index.php/revistaaec/article/view/96/318. Acesso em: 2 fev. 2020. 
MORONI, José Antônio. Os cinco eixos do controle social. In: CANELA, Guilherme; NASCIMENTO, Solano. Acesso à informação e controle social das políticas. Brasília, DF: ANDI, 2009. Disponível em: http://www.acessoainformacao.gov.br/central-de-conteudo/publicacoes/arquivos/acesso-a-informacao-e-controle-social-das-políticas-publicas.pdf/view. Acesso em: 10 fev. 2020.

ORGANIZAÇÃO DAS NAÇÕES UNIDAS. Resolução n. 217 A III - Declaração Universal dos Direitos Humanos. Assembleia Geral das Nações Unidas, 1948. Paris, França. Disponível em: http://www. ohchr.org/EN/UDHR/Pages/Language.aspx?LangID=por. Acesso em: 28 jan. 2020.

ORGANIZAÇÃO DAS NAÇÕES UNIDAS. Resolução n. 2200-A (XXI) - Pacto Internacional sobre Direitos Civis e Politicos. Assembleia Geral das Nações Unidas, 1966. Disponível em: http://www. refugiados.net/cid_virtual_bkup/asilo2/2pidcp.html. Acesso em: 14 fev. 2020.

ORGANIZAÇÃO DOS ESTADOS AMERICANOS. Convenção Americana sobre Direitos Humanos Pacto de San Jose da Costa Rica. San José, Costa Rica: Conferência Especializada Interamericana sobre Direitos Humanos, 1969. Disponível em: https://www.cidh.oas.org/basicos/portugues/c.convencao_ americana.htm. Acesso em: 28 jan. 2020.

ORGANIZAÇÃO DOS ESTADOS AMERICANOS. Resolução 1932 (XXXIII $\square O / 03$ ). Acesso à Informação Pública: Fortalecimento da Democracia. Assembleia Geral Comissão Interamericana, 2003. Disponível em: http://www.oas.org/juridico/portuguese/ag03/agres1932.htm. Acesso em: 28 jan. 2020.

PETTIT, Phillip. Liberdade como antipoder. Política \& Sociedade, Florianópolis, v. 9, n. 16, p. 11-50, 2010. Disponível em: https://periodicos.ufsc.br/index.php/política/article/view/2175-7984.2010v9n16p11. Acesso em: 29 jan. 2020.

PETTIT, Phillip. Republicanismo: una teoria sobre la libertad y el gobierno. Barcelona: Paidos Iberica Ediciones, 1999.

PETTIT, Phillip. Teoria da Liberdade. 5. ed. Belo Horizonte: Del Rey Internacional, 2007.

PINTO, Ricardo Leite. Uma introdução ao neo-republicanismo. Análise Social, Lisboa, Portugal, v. 36, n. 158/159, p. 461-485, 2001. Disponível em: http://analisesocial.ics.ul.pt/documentos/1218726793R5fMU7mi5Rz78WY7.pdf. Acesso em: 13 fev. 2020.

RODRIGUES, Cíntia Luzardo. Principais aspectos do neorrepublicanismo de Phillip Pettit. Pensamento Plural, Pelotas, n. 6, p. 35-56, 2010. Disponível em: https://periodicos.ufpel.edu.br/ojs2/ index.php/pensamentoplural/article/viewFile/3654/2990. Acesso em: 4 jan. 2020.

SALGADO, Eneida Desiree. Políticas Públicas, Inclusão Social e Desenvolvimento Democrático. Revista Eurolatinoamericana de Derecho Administrativo, Santa Fé, Argentina, v. 2, n. 1, p. 89-99, 2015. Disponível em: http://bibliotecavirtual.unl.edu.ar/ojs/index.php/Redoeda/article/view/4631. Acesso em: 3 fev. 2020.

SILVA, Ricardo. Participação como contestação: a ideia de democracia no neo-republicanismo de Philip Pettit. Política \& Sociedade, Florianópolis, v. 6, n. 11, p. 198-220, 2007. Disponível em: https://periodicos.ufsc.br/index.php/politica/article/view/1287. Acesso em: 30 jan.2020.

SILVA, Ricardo. Republicanismo neo-romano e democracia contestatória. Revista de Sociologia Política, Curitiba, v. 19, n. 39, p. 35-51, jun. 2011. Disponível em: http://www.scielo.br/scielo.php?script=sci_arttext\&pid=S0104-44782011000200004\&Ing=en\&nrm=iso. Acesso em: 30 jan. 2020. 
SUPREMO TRIBUNAL FEDERAL. Plenário confirma liminar que impediu restrições na Lei de Acesso à Informação durante pandemia. Notícia, 30 abr. 2020. Disponível em: http://portal.stf.jus. br/noticias/verNoticiaDetalhe.asp?.idConteudo=442475\&ori=1. Acesso em: 30 abr. 2020.

TRASNPARÊNCIA BRASIL. Quase metade dos principais órgãos públicos brasileiros descumprem a Lei de Acesso à Informação. Achados e perdidos, [S. 1.], set. 2017. Disponível em: http://www. achadosepedidos.org.br/uploads/publicacoes/Relat\%C3\%B3rio_LAI_16022018.pdf. Acesso em: 29 jul. 2020.

YAZIGI, Alejandro Ferreiro. Dinero, Política y Transparencia: El imperativo democrático de combatir la corrupción. In: CONFERÊNCIA INTERNACIONAL ANTICORRUPÇÃO (IACC), 9., 1999, Durban, África do Sul. Anais [...]. 1999. Disponível em: http://anterior.cdc.gob.cl/wp-content/ uploads/2015/03/AFERREIRO.pdf. Acesso em: 28 jan. 2020. 
